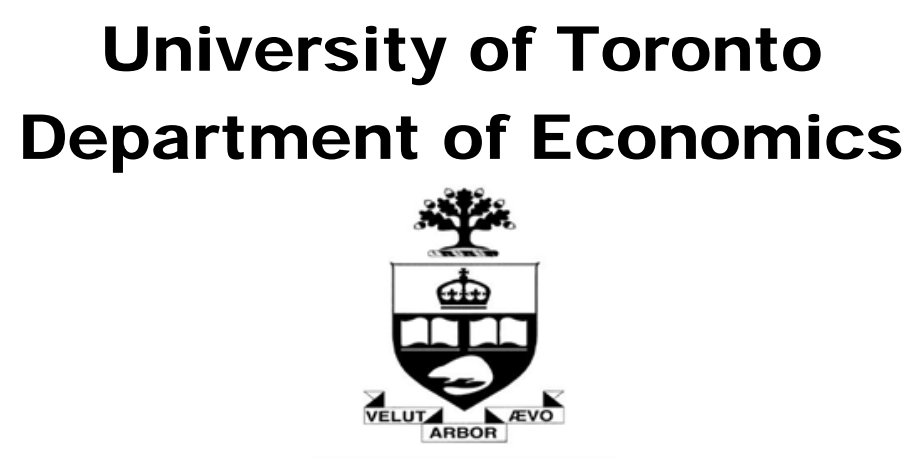

Working Paper 329

Efficiency Improvement from Restricting the Liquidity of Nominal Bonds

By Shouyong Shi

August 12, 2008 


\title{
Efficiency Improvement from Restricting the Liquidity of Nominal Bonds*
}

\author{
Shouyong Shi \\ Department of Economics, University of Toronto \\ 150 St. George Street, Toronto, Ontario, Canada, M5S 3G7 \\ (email: shouyong@chass.utoronto.ca) \\ (fax: 416-978-6713; phone: 416-978-4978)
}

This version: January 2008

\begin{abstract}
This paper addresses why it is beneficial for a society to restrict the use of nominal bonds as a means of payment for goods. The model has a centralized asset market and a decentralized goods market. Individuals face matching shocks that affect the marginal utility of consumption, but they cannot insure, borrow or trade assets against such risks. The government imposes a legal restriction to prohibit nominal bonds from being used as a means of payment in a subset of trades. I show that this partial legal restriction can improve the society's welfare. In contrast to the literature, the efficiency role of the restriction exists in the steady state and it does not require the households to be able to trade assets after receiving the shocks. Moreover, even when lump-sum taxes are available, the efficiency role continues to exist under a condition that induces optimal money growth to be above the Friedman rule.
\end{abstract}

Keywords: Nominal Bonds; Money; Efficiency; Return dominance.

JEL Classification: E40.

\footnotetext{
* An anonymous referee and an associate editor gave extensive comments on previous versions of the paper that led to significant improvements. I have also benefited from the comments by Guillaume Rocheteau, Neil Wallace and Randall Wright, and by the participants of the workshops and conferences at UQAM, Basel, University of Hong Kong, the Federal Reserve of Cleveland, the Federal Reserve Bank of New York, the Society for Economic Dynamics Meetings (Vancouver, 2006), and the Bank of Canada. I gratefully acknowledge the financial support from the Bank of Canada Fellowship and from the Social Sciences and Humanities Research Council of Canada. The opinion expressed here is my own and does not represent the view of the Bank of Canada.
} 


\section{Introduction}

Nominal bonds have coexisted with fiat money for a long time. For countries like the U.S. in the recent history, government bonds bear little default risk and have all the intrinsic features that money has, but they are discounted and bear positive nominal interest. This so-called return dominance has required resources to maintain it. In many countries, different branches of the government are created to manage money and bonds separately. In the U.S., for example, the Federal Reserve Bank issues money, while the Treasury issues government bonds. These facts raise the following question: why should a society distinguish bonds from money? Put differently, can return dominance improve efficiency?

The answer is no in most models in the literature. As early as Hicks (1939), monetary theory has explained return dominance by imposing restrictions on bonds, such as reserve requirements, cash in advance, and money in the utility function. These restrictions reduce the extent to which bonds can serve as a medium of exchange. To compensate for the lower liquidity, bonds must earn positive nominal interest in the equilibrium. In most models, however, these differences in liquidity and returns distort the allocation of resources. By eliminating the restrictions, the society is better off.

This result that return dominance does not improve efficiency is unsatisfactory. It fails to explain why return dominance has survived for such a long time or to justify the resources devoted to maintaining return dominance. On the policy side, the result fails to provide an efficiency basis for monetary policy. Return dominance is necessary for monetary policy to achieve its effects. For example, open market operations exploit the positive discount on bonds, and the overnight market relies on collateral that has a higher rate of return than money. In the extensive literature on open market operations (e.g., Lucas, 1990), return dominance reduces efficiency, but eliminating return dominance also eliminates the real effect of monetary policy. It is desirable to analyze the effects of monetary policy in a model where return dominance and illiquid bonds enhance efficiency.

To address the main question, I introduce nominal bonds and a legal restriction into a search model of money (Shi, 1997). The government sells bonds for money in a centralized 
market. In a separate market, goods are sold in a decentralized way. That is, agents are matched in pairs, trading histories are private, and every trade requires a medium of exchange. Each good can be either red or green, which is determined after individuals are matched. The two colors are equally costly to produce, but they yield different marginal utilities. The marginal utility of red goods relative to green goods is $\theta$. Although green goods can be purchased with both money and bonds, a legal restriction prohibits the use of bonds as the means of payment for red goods.

In the first version of the current model, the legal restriction is assumed to be enforced costlessly. I show that the legal restriction can increase the society's steady-state welfare when the relative taste for red goods, $\theta$, is less than one, but not too small. The reason for this result is simple. The legal restriction reduces the quantity of red goods and increases the quantity of green goods traded in a match. When $\theta$ is less than one, this shift of consumption from red goods to green goods reduces the gap between the marginal utilities of the two goods and, hence, increases the expected utility. Put differently, bonds under the legal restriction serve as partial insurance against the matching shocks.

This efficiency role exists for all money growth rates above the Friedman rule, i.e., above the discount factor. However, the role vanishes at the Friedman rule, where holding money provides perfect self insurance against the matching shocks. Because the Friedman rule is optimal in a wide class of models, an important issue is whether the legal restriction can continue to improve efficiency when monetary policy is set optimally.

To address this issue, I explore the effect of money growth on the extensive margin of trade, i.e., the number of trades in the goods market. The number of trades is an important consideration for efficiency, in addition to the quantity of goods traded, when the goods market is decentralized. Search externalities in the market can make the number of trades generically inefficient. To reduce this inefficiency, a policy should bring the division of the match surplus between buyers and sellers closer to the principle described by Hosios (1990). I specify the condition under which money growth above the Friedman rule can achieve this improvement. Under this condition, restricting the liquidity of nominal bonds improves the society's welfare even under optimal money growth. Note that it is difficult 
to obtain this result in traditional models because they assume a centralized goods market, in which the extensive margin of trade is unimportant.

In the second version of the current model, I introduce government sellers to enforce the restriction. Like a private seller, a government seller can produce either red or green goods, and the color is determined by the shock in each match. In contrast to a private seller, a government seller refuses to accept bonds as a means of payment in a trade where the good is red. In all other trades, including those where government sellers produce green goods, the buyers can use both money and bonds as payments. All the main results in the first version of the model continue to hold in this version of the model.

Bryant and Wallace (1984) are among the first who have examined a legal restriction on nominal bonds. In their model of overlapping generations, bonds have large denominations, and a legal restriction prohibits intermediaries from issuing small-denomination bills. Because the indivisibility of bonds makes an agent's consumption set non-convex, there is price discrimination depending on whether agents hold bonds. This discrimination can increase the expected utility when lump-sum taxes are not possible. In contrast, my model does not have indivisibility, and the legal restriction directly prevents agents from using bonds as payments in a subset of trades. ${ }^{1}$ Moreover, the legal restriction can continue to improve efficiency in my model even when it is feasible for the government to follow the Friedman rule by collecting lump-sum taxes.

Kocherlakota (2003) published another well-known paper on the efficiency role of illiquid bonds. Modeling the goods market as centralized exchange, Kocherlakota introduces taste shocks in the first period of the economy. He shows that illiquid bonds can increase the expected utility if agents can trade assets after observing taste shocks. Agents with high taste shocks sell bonds for money to increase current consumption, while agents with low taste shocks buy bonds to increase future consumption. Thus, the asset trade enables agents to partially smooth marginal utility. I shut down this asset trade by assuming that

\footnotetext{
${ }^{1}$ It is awkward to introduce non-convexity into my model. Because each household experiences a large number of trades, consumption sharing within each household convexifies the model even if indivisible bonds are introduced. Also, note that the type of non-convexity in Bryant and Wallace (1984) is eliminated if individuals can participate in lotteries that allocate the large-denomination bonds.
} 
the shocks occur within the matches, at which time individuals are separated from each other and hence cannot trade assets. This deliberate assumption allows me to focus on a different mechanism of partial insurance achieved by illiquid bonds, i.e., smoothing the marginal utility between matches rather than between agents. ${ }^{2}$

There are two other main differences between this paper and the one by Kocherlakota (2003). First, the efficiency role of illiquid bonds exists in Kocherlakota's model only in one period, and it is challenging to extend his model in a tractable way to sustain this efficiency role. My model is tractable and the legal restriction can improve efficiency in the steady state. Second, allowing for lump-sum taxes eliminates the efficiency role of illiquid bonds in Kocherlakota (2003), but not necessarily so in this paper.

Some other related papers are as follows. Wallace (1983) argues explicitly that legal restrictions on nominal bonds are inefficient in an overlapping generations model. Aiyagari et al. (1996) examine the competition between money and bonds in a search model, but their results are difficult to interpret due to the assumption of indivisible money and bonds. I eliminate this assumption using the model of Shi (1997). Finally, Sun (2005) and Boel and Camera (2006) establish an efficiency role of illiquid bonds but, as Kocherlakota (2003), they assume that individuals can trade assets after observing the taste shocks. ${ }^{3}$

\section{A Search Economy with the Legal Restriction}

\subsection{Households, Matches and Assets}

Consider a discrete-time economy with many types of households. In each type, the number of households is large and normalized to one. These households desire a particular good, called the households' consumption good, which is produced by some other types of households. All goods are perishable at the end of each period and all households have the

\footnotetext{
${ }^{2}$ Exploring a different mechanism can lead us to a robust role of illiquid bonds. If agents can trade in the asset market after observing the taste shocks, they may also be able to borrow and lend, either directly or indirectly through the government (e.g., Berentsen, Camera and Waller, 2007). Such borrowing and lending could supersede the partial insurance role of illiquid bonds emphasized by Kocherlakota (2003).

${ }^{3}$ In a previous paper (Shi, 2005), I construct a search model where money and bonds are divisible and where a legal restriction exists. However, that paper does not examine the efficiency role of the legal restriction. Neither does Andolfatto (2006), who extends the model of Wallace (1983).
} 
same discount factor $\beta \in(0,1)$.

A household consists of a large number of members (normalized to one) who share consumption each period and regard the household's utility as the common objective. This assumption maintains tractability by making the distribution of money holdings across households degenerate despite the presence of random matching. ${ }^{4}$ I select an arbitrary household as the representative household. Throughout this paper, lower-case variables denote this representative household's choices, while upper-case variables denote the corresponding choices of other households or aggregate variables.

The representative household divides the members into three groups: sellers/producers (a fraction $\sigma$ ), buyers (a fraction $n-\sigma$ ), and leisure seekers (a fraction $1-n$ ). A seller can produce and sell goods, while a buyer buys consumption goods for the household. The household chooses $n$, the fraction of market participants. To simplify the analysis, I assume that $\sigma$ is constant so that choosing $n$ is equivalent to choosing the measure of buyers. ${ }^{5}$

Each type of goods can be one of the two colors, "red" or "green". The cost of producing the two colors is specified by the same disutility function, $\psi($.$) . The utility generated by$ a good of color $i$ is $\theta^{i} u\left(c^{i}\right)$, where $i \in\{R, G\}, \theta^{G}=1$ and $\theta^{R}=\theta(>0)$. The function $\psi$ satisfies: $\psi(0)=0, \psi^{\prime}(0)=0, \psi^{\prime}(q)>0$ and $\psi^{\prime \prime}(q)>0$ for all $q>0$. The function $u$ satisfies: $u^{\prime}>0, u^{\prime \prime}<0, u^{\prime}(0)=\infty$ and $u^{\prime}(\infty)=0 .{ }^{6}$ In addition, the utility of leisure in the household is $h(1-n)$, where $h(0)=0, h^{\prime}(0)=\infty, h^{\prime}>0$ and $h^{\prime \prime}<0$.

In the goods market, buyers and sellers are randomly matched in pairs where there is no double coincidence of wants. A trade match is a match in which the seller can produce the consumption good of the buyer's household. The total number of trade matches per household in a period is assumed to be $\alpha N$, where $\alpha>0$ is a constant and $N$ is the measure of market participants per household. A buyer encounters a trade match with probability $\alpha N /(N-\sigma)$, and a seller with probability $\alpha N / \sigma$. Assume that $\alpha$ is sufficiently small so

\footnotetext{
${ }^{4}$ The assumption of large households is a modeling device extended from Lucas (1990), which is meant to capture an individual agent's allocation of time over different activities (see Shi, 1997). For an alternative way to make the distribution of asset holdings degenerate, see Lagos and Wright (2005).

${ }^{5}$ See Shi (2001) for a search model where the measures of buyers and sellers are both endogenous.

${ }^{6}$ The analytical results hold for a more general specification $u\left(c^{i}, \theta^{i}\right)$, where the derivative of $u$ with respect to $c$ is increasing in $\theta$.
} 
that these expressions are bounded in $[0,1]$.

Once a buyer and a seller are matched, the seller receives a shock that determines whether he can produce the red or the green good, with probability $1 / 2$ for each color. Let me call this shock a matching shock, because it occurs within each match. A trade match in which a good of color $i$ is produced is called a color $i$ trade. The matching shocks are identically and independently distributed across matches and over time. For each household, the number of trade matches of each color is deterministic because each household consists of a large number of market participants.

In each trade, the buyer makes a take-it-or-leave-it offer. This assumption simplifies the determination of the trading quantities. Note that the assumption does not lead to a trivial division of household members because of the earlier assumption that the measure of sellers is fixed. For an analysis where the measures of buyers and sellers are both endogenous and where the surplus division between a buyer and a seller is interior, see Shi (2001).

As is common in monetary models, the trading history of each household is private information. Thus, credit cannot be used and every trade entails a medium of exchange. Two assets can perform this role, fiat money and nominal bonds. Both assets are issued by the government and can be stored without cost. The two assets are intrinsically worthless; i.e., they do not yield direct utility or facilitate production. Bonds are default-free, oneperiod bonds. At maturity, a bond can be redeemed for one unit of money. Without loss of generality, I assume that bonds are redeemed immediately at maturity. ${ }^{7}$

The only difference between money and bonds is created by a partial legal restriction. While money can be used in both red and green trades, the legal restriction forbids the use of bonds as a means of payment in red trades. For now, I assume that the legal restriction is always enforced costlessly. The main results of the model hold even when government agents are introduced to enforce the legal restriction (see section 4).

In addition to the goods market, there is an asset market where the government sells new bonds for money at an equilibrium price and redeems matured bonds. Let $z M$ be the

\footnotetext{
${ }^{7}$ In principle, a household can choose not to redeem the bonds at maturity and, instead, use them as a medium of exchange. However, such a choice is not optimal if there is a slight chance that the bonds will be rejected in trade as a result of the legal restriction (see Shi, 2005).
} 
nominal amount of new bonds sold in each period, where $z \in(0, \infty)$ is a constant and $M$ is the average stock of money per household. The government prints money and collects lump-sum taxes to pay for the redemption of matured bonds. To focus on a stationary equilibrium, I assume that the effect of open market operations on the money supply is sterilized by lump-sum transfers. That is, the transfers keep money holdings per household growing at a constant (gross) rate $\gamma \geq \beta$. When $\gamma<1$, the transfers are negative and, hence, are taxes. Normalize all nominal quantities and prices of goods by $M$.

\subsection{Timing of Events and Capital Market Imperfections}

Pick an arbitrary period $t$ and suppress the time index $t$. Figure 1 depicts the timing of events in a period. First, the asset market opens. The representative household redeems matured bonds, receives lump-sum monetary transfers, $T$, and purchases new bonds. The (normalized) amount of new bonds sold by the government is $z$, which is exogenous. After the trade, the household's holdings consist of money, $m$, and bonds, $b$. Then, the asset market is closed and will remain closed for the rest of the period.

\begin{tabular}{|c|c|c|c|c|}
\hline $\begin{array}{l}t \\
\text { asset market }\end{array}$ & $\begin{array}{l}(m, b) \\
\text { measured }\end{array}$ & & $\begin{array}{l}\text { matching } \\
\text { shocks }\end{array}$ & \\
\hline $\begin{array}{l}\text { redemption; } \\
\text { transfers, } T ; \\
\text { new bonds, } b\end{array}$ & $\begin{array}{l}\text { bonds mkt } \\
\text { closed until } \\
\text { next period }\end{array}$ & $\begin{array}{l}\text { choices: } \\
n \\
\left(q^{i}, x^{i}\right)\end{array}$ & $\begin{array}{l}\text { trades } \\
\text { in goods: }\end{array}$ & consume \\
\hline
\end{tabular}

Figure 1. Timing of events in a period

Next, the household chooses $n$, the fraction of members who will participate in the goods market. Also, the household gives the assets to the buyers and instructs them on the quantities of trade. Because the matching shocks have not realized yet, the household allocates the assets evenly among the buyers. Each buyer gets $m /(n-\sigma)$ units of money and $b /(n-\sigma)$ units of bonds. Moreover, the household gives the instructions to its buyers on the offers they will make. Contingent on the realization of the matching shock, $i \in\{R, G\}$, an offer consists of the amount of goods to be purchased, $q^{i}$, and the amount of assets to be spent, $x^{i}$. Because of the legal restriction, $x^{R}$ must consist of only money. 
Afterward, the traders go to the goods market. Buyers and sellers are matched in pairs. In each match, the matching shock is realized to determine whether the seller can produce red or green goods. The buyers make the offers instructed earlier by the household. After the trade, the members bring the receipts of assets and goods back to the household. All members in the household share the same consumption. Then, the period ends.

Because all the households are symmetric, borrowing and lending between households is irrelevant in this model. What a household would like to do is to redistribute assets between matches that have received different shocks, but this redistribution is not possible because the exchange is decentralized. This inability to trade assets between matches captures the capital market imperfection that the asset market is closed sometimes when individuals need liquidity, albeit for a short time, or that it is costly to go between the asset market and the goods market. As explained in the introduction, introducing these imperfections allows me to uncover a new channel through which illiquid bonds can improve efficiency, as opposed to the channel in Kocherlakota (2003). ${ }^{8}$

\subsection{Quantities of Trade in the Matches}

Let $m$ be the household's holdings of money and $b$ the holdings of bonds immediately after trading in the asset market. The holdings are normalized by the aggregate stock of money holdings per household. Let $v(m, b): R_{+} \times R_{+} \rightarrow R$ be the household's value function. Let $\omega^{j}$ be the shadow value of next period's asset $j(=m, b)$. That is,

$$
\omega^{m} \equiv \frac{\beta}{\gamma} \frac{\partial}{\partial m_{+1}} v\left(m_{+1}, b_{+1}\right), \quad \omega^{b} \equiv \frac{\beta}{\gamma} \frac{\partial}{\partial b_{+1}} v\left(m_{+1}, b_{+1}\right),
$$

where the subscript $\pm j$ stands for $t \pm j$. The future value of an asset is discounted by money growth $\gamma$, as well as $\beta$, because $m_{+1}$ is normalized by next period's money stock. Other households' values of the assets are denoted similarly with $\Omega$.

In each trade, the buyer makes a take-it-or-leave-it offer. The offer must induce the seller to trade. Because the seller's surplus in a color $i$ trade is equal to $\left[\Omega^{m} x^{i}-\psi\left(q^{i}\right)\right]$, the

\footnotetext{
${ }^{8}$ Note also that insurance contracts between households are irrelevant here, because all households have the same consumption and output. For dynamic contracts in a monetary model with private information, see Temzelides and Williamson (2001).
} 
offer $\left(q^{i}, x^{i}\right)$ must satisfy:

$$
x^{i}=\psi\left(q^{i}\right) / \Omega^{m}, \quad i=R, G .
$$

In addition, the buyer cannot offer more assets than what he can use; that is,

$$
\begin{aligned}
& x^{R} \leq \frac{m}{n-\sigma}, \\
& x^{G} \leq \frac{m+b}{n-\sigma} .
\end{aligned}
$$

For a red trade, (2.3) embodies the legal restriction. For a green trade, (2.4) shows that it is unnecessary to specify how an offer consists of money and bonds. The two assets have the same continuation value. Upon exiting from the trade, the only thing the household can do with the assets is to bring them to the next period, at which time bonds will mature and can be redeemed for money at par. More precisely, the two assets have the same marginal value $\omega^{m}$ to the buyer and $\Omega^{m}$ to the seller.

If either (2.3) or (2.4) binds, money generates liquidity services or non-pecuniary returns. In contrast, bonds yield liquidity services only if (2.4) binds. Bonds are perfect substitutes for money if they have the same value as money, i.e., if $\omega^{b}=\omega^{m}$.

\subsection{A Household's Decision Problem}

In each period, the household chooses the measure of market participants, $n$, the quantities of trade, $\left(q^{i}, x^{i}\right)$, consumption, $c^{i}$, and future asset holdings, $\left(m_{+1}, b_{+1}\right)$. Taking other households' decisions as given, the household solves the following problem:

$$
(P H) \quad v(m, b)=\max \left\{\sum_{i=R, G}\left[\theta^{i} u\left(c^{i}\right)-\frac{\alpha N}{2} \psi\left(Q^{i}\right)\right]+h(1-n)+\beta v\left(m_{+1}, b_{+1}\right)\right\}
$$

where

$$
c^{i}=\frac{\alpha N(n-\sigma)}{2(N-\sigma)} q^{i}, \quad i \in\{R, G\} .
$$

The constraints are (2.2), (2.3), (2.4) and the following:

$$
m_{+1}+S_{+1} b_{+1}=\frac{1}{\gamma}\left[m+b+\frac{\alpha N}{2}\left(X^{R}+X^{G}\right)-\frac{\alpha N(n-\sigma)}{2(N-\sigma)}\left(x^{R}+x^{G}\right)\right]+T_{+1},
$$

where $S_{+1}$ is the nominal price of bonds in the next period. 
In (2.6), the total number of color $i$ trades that the household's buyers experience is $\alpha N /[2(N-\sigma)]$. Multiplying it by the number of buyers in the household, $n-\sigma$, and by the quantity of goods in each color $i$ trade yields the level of consumption. Similarly, total disutility incurred by the household's sellers in producing color $i$ goods is $\psi\left(Q^{i}\right) \alpha N / 2$, where $Q^{i}$ is the quantity proposed by a buyer of other households.

Equation (2.7) describes how the household's asset holdings evolve. Starting at the time in a period immediately after trading in the asset market (see Figure 1), the household's portfolio of asset holdings is $(m, b)$. In the goods market, the household receives an amount

of assets, $\frac{\alpha N}{2}\left(X^{R}+X^{G}\right)$, by selling goods and spends an amount, $\frac{\alpha N(n-\sigma)}{2(N-\sigma)}\left(x^{R}+x^{G}\right)$. In addition, the household will redeem matured bonds for money and receive monetary transfers at the beginning of next period. The resulting amount of assets is given by the right-hand side of (2.7), which will be used to update the portfolio.

\subsection{Optimal Choices}

Let $\lambda^{R}$ be the shadow price of (2.3), and $\lambda^{G}$ of (2.4). To simplify the formulas, multiply $\lambda^{i}$ by the number of color $i$ trades, $\frac{\alpha N(n-\sigma)}{2(N-\sigma)}$, before incorporating the constraint into the Lagrangian. The optimal choices of $q^{i}$ and $b_{+1}$ satisfy the following conditions:

$$
\begin{gathered}
\theta^{i} u^{\prime}\left(c^{i}\right)=\left(\omega^{m}+\lambda^{i}\right) \frac{\psi^{\prime}\left(q^{i}\right)}{\Omega^{m}}, i=R, G . \\
S_{+1}=\omega^{b} / \omega^{m} .
\end{gathered}
$$

For $m$ and $b$, the envelope conditions are as follows:

$$
\begin{gathered}
\frac{\gamma}{\beta} \omega_{-1}^{m}=\omega^{m}+\frac{\alpha N}{2(N-\sigma)}\left(\lambda^{G}+\lambda^{R}\right), \\
\frac{\gamma}{\beta} \omega_{-1}^{b}=\omega^{m}+\frac{\alpha N}{2(N-\sigma)} \lambda^{G} .
\end{gathered}
$$

The optimal choice of $n$ is characterized by:

$$
h^{\prime}=\frac{\alpha N}{2(N-\sigma)} \sum_{i=R, G}\left\{\theta^{i} u^{\prime}\left(c^{i}\right)\left[q^{i}-\frac{\psi\left(q^{i}\right)}{\psi^{\prime}\left(q^{i}\right)}\right]\right\} .
$$

In (2.8), the quantity of assets that a buyer must give to the seller in order to obtain one unit of color $i$ good is $\psi^{\prime}\left(q^{i}\right) / \Omega^{m}$. The cost of each unit of asset is equal to the future 
value of the asset, $\omega^{m}$, plus the shadow cost of the asset constraint, $\lambda^{i}$. Thus, (2.8) requires that the cost of the assets to a buyer be equal to the marginal utility of consumption of a color $i$ good. (2.9) states the fact that the nominal price of bonds is equal to the relative value of bonds to money before the goods market opens. Thus, bonds are discounted only if they are not perfect substitutes for money in the goods market.

To explain the envelope conditions, take the condition for money, (2.10), for example. The current value of money is given by the left-hand side of $(2.10)$, where $\omega_{-1}^{m}$ is multiplied by $\gamma / \beta$, because $\omega_{-1}^{m}$ is defined as the current value of money discounted to one period earlier. The right-hand side of (2.10) consists of the (discounted) future value of money, $\omega^{m}$, and expected liquidity services generated by money in the goods market. Thus, (2.10) requires the current value of money to be equal to the future value of money plus the expected liquidity services generated by money. The condition for bonds, (2.11), is similar except that bonds do not generate liquidity services in red trades. Thus, $\omega^{b}<\omega^{m}$ if and only if $\lambda^{R}>0$, i.e., if the legal restriction binds.

Finally, (2.12) requires that the marginal disutility of allocating a member to the goods market (as a buyer) is equal to the expected gain. In the goods market, a buyer encounters a color $i$ trade with probability $\alpha N /[2(N-\sigma)]$. The net gain from a color $i$ trade to the buyer's household is $\left[\theta^{i} u^{\prime}\left(c^{i}\right) q^{i}-\left(\omega+\lambda^{i}\right) x^{i}\right]$. After substituting $x^{i}$ from (2.2) and $\lambda^{i}$ from (2.8), the net gain becomes the expression inside the summation in (2.12).

\subsection{Stationary Equilibrium}

An equilibrium consists of the representative household's choices, $\left(n, q, x, c, m_{+1}, b_{+1}\right)$, the value function $v$, the shadow values of assets $\left(\omega^{m}, \omega^{b}\right)$, and other households' choices such that the following requirements are met. (i) Optimality: given other households' choices, the household's choices solve $(P H)$ and the value function satisfies (2.5); (ii) symmetry: the choices and shadow prices are the same across the households; (iii) clearing of the bonds market: $b=z$; (iv) positive and finite values of assets: $0<\omega_{-1}^{m} m<\infty$ and $0<\omega_{-1}^{b} b<\infty$; (v) stationarity: all real variables and the values $\left(\omega_{-1}^{m} m, \omega_{-1}^{b} b\right)$ are constant.

The requirement (iv) restricts the values of the two assets to be positive in order to 
examine coexistence, and finite in order to use the first-order conditions to characterize the optimal decisions. Moreover, (iii) implies that the choice of $b$ is interior, while stationarity implies $\omega_{-1}^{m}=\omega^{m}$ and $\omega_{-1}^{b}=\omega^{b}$. Symmetry implies $m=M=1$. In the following analysis, I will equate the upper-case variables to the corresponding lower-case variables.

Let me characterize the equilibrium with $\gamma>\beta$. (To obtain the allocation under the Friedman rule, one can take the limit $\gamma \downarrow \beta$.) With $\gamma>\beta$, either $\lambda^{R}>0$ or $\lambda^{G}>0$ or both. If both $\lambda^{\prime}$ es were zero, a stationary equilibrium would fail to exist for all $\gamma>\beta$. Thus, there are three cases of the equilibrium, depending on whether one or two of the asset constraints bind. To characterize the cases, define $\mu(n)$ and $f(k, n)$ as follows:

$$
\begin{gathered}
\mu(n) \equiv \frac{n-\sigma}{\alpha n}\left(\frac{\gamma}{\beta}-1\right), \\
\frac{u^{\prime}\left(\frac{\alpha n}{2} f(k, n)\right)}{\psi^{\prime}(f(k, n))}=k, \text { for } k>0 .
\end{gathered}
$$

The quantity of goods in a color $i$ trade is $f\left(k / \theta^{i}, n\right)$, where $k$ differs in the three cases. Note that $f(k, n)$ decreases in $(k, n)$. For all $n \in(\sigma, 1), \gamma>\beta$ implies $\mu>0$.

Consider first the case where $\lambda^{R}=0<\lambda^{G}$. Refer to this case as Case PS (for perfect substitutability) and denote the quantity of goods in a color $i$ trade as $q_{1}^{i}$. Because the legal restriction does not bind in this case, bonds are perfect substitutes for money. Precisely, (2.10) and (2.11) imply $\omega^{b}=\omega^{m}$, and (2.9) yields $S=1$. To obtain $q_{1}^{G}$, substitute $\lambda^{G}$ from (2.8) and $\lambda^{R}=0$ into (2.10). This procedure yields an equation for $q_{1}^{G}$. Setting $\lambda^{R}=0$ in (2.8), I obtain an equation for $q_{1}^{R}$. Using $f$ defined in (2.14), I express:

$$
q_{1}^{G}(n) \equiv f(1+2 \mu(n), n), \quad q_{1}^{R}(n) \equiv f\left(\frac{1}{\theta}, n\right) .
$$

Now consider the case where $\lambda^{R}>0=\lambda^{G}$. Refer to this case as Case TS (for terrible substitutability) and denote the quantity of goods in a color $i$ trade as $q_{3}^{i}$. Because the legal restriction binds in this case, $\omega^{b}<\omega^{m}$. (2.11) implies $\omega_{-1}^{b}=\omega^{m} \beta / \gamma$. Because $\omega^{b}=\omega_{-1}^{b}$, (2.9) yields $S=\beta / \gamma$. As in the above approach, I obtain:

$$
q_{3}^{G}(n) \equiv f(1, n), \quad q_{3}^{R}(n) \equiv f\left(\frac{1+2 \mu(n)}{\theta}, n\right) .
$$


Finally, consider the case where $\lambda^{R}>0$ and $\lambda^{G}>0$. Refer to this case as Case IS (for imperfect substitutability) and denote the quantity of goods in a color $i$ trade as $q_{2}^{i}$. This case lies between Case PS and Case TS. As in Case TS, bonds are not perfect substitutes for money in the goods market, because $\lambda^{R}>0$. However, since bonds yield liquidity services in green trades, they are not discounted by as much as in Case TS. Substituting $\omega_{-1}^{b}=S \omega_{-1}^{m}$ into (2.11), I obtain an equation for $q_{2}^{G}$, given $S$. Subtracting (2.11) from (2.10), I obtain an equation for $q_{2}^{R}$. Define

$$
k^{G}(S, n)=1+\frac{2(n-\sigma)}{\alpha n}\left(\frac{\gamma}{\beta} S-1\right), \quad k^{R}(S, n)=\frac{1}{\theta}\left[1+\frac{2(n-\sigma) \gamma}{\alpha n \beta}(1-S)\right] .
$$

Express the quantities of goods traded as

$$
q_{2}^{i}=Q_{2}^{i}(S, n) \equiv f\left(k^{i}(S, n), n\right), \text { for } i=G, R \text {. }
$$

Because the two asset constraints bind in this case, $Q_{2}^{G}$ and $Q_{2}^{R}$ satisfy:

$$
\frac{\psi\left(Q_{2}^{G}(S, n)\right)}{\psi\left(Q_{2}^{R}(S, n)\right)}-(1+z)=0 .
$$

This equation determines $S=S(n)$, for any given $n$. Then, $q_{2}^{i}(n)=Q_{2}^{i}(S(n), n)$.

In each case, $n$ solves (2.12). Let the equilibrium solution for $n$ be $n_{1}$ in Case PS, $n_{2}$ in Case IS, and $n_{3}$ is TS. The following proposition describes existence and uniqueness of the equilibrium (see Appendix A for a proof):

Proposition 2.1. Define $\gamma_{0}=\beta\left[1+\frac{\alpha}{2}(1+\theta)\right]$. Assume that $\gamma>\beta$ and that $z$ is sufficiently close to zero. If $\gamma<\gamma_{0}$, then a unique equilibrium exists and is characterized as in Table 1, where $\theta_{1}$ and $\theta_{3}$ are specified in Appendix A.

Table 1. Three cases of the equilibrium

\begin{tabular}{|c|c|c|c|}
\hline & Case PS & Case IS & Case TS \\
\hline existence & $0<\theta \leq \theta_{1}(<1)$ & $\theta_{1}<\theta<\theta_{3}$ & $\theta \geq \theta_{3}$ \\
\hline asset constraints & $\lambda^{R}=0<\lambda^{G}$ & $\lambda^{R}>0, \lambda^{G}>0$ & $\lambda^{R}>0=\lambda^{G}$ \\
\hline bond price & $S=1$ & $S \in\left(\frac{\beta}{\gamma}, 1\right)$ & $S=\frac{\beta}{\gamma}$ \\
\hline \# of traders & $n_{1} \in(\sigma, 1)$ & $n_{2} \in\left(n_{1}, n_{3}\right)$ & $n_{3} \in(\sigma, 1)$ \\
\hline red goods & $q_{1}^{R}\left(n_{1}\right)$ & $q_{2}^{R}\left(n_{2}\right) \in\left(q_{1}^{R}\left(n_{1}\right), q_{3}^{R}\left(n_{3}\right)\right)$ & $q_{3}^{R}\left(n_{3}\right)$ \\
\hline green goods & $q_{1}^{G}\left(n_{1}\right)$ & $q_{2}^{G}\left(n_{2}\right)$ & $q_{3}^{G}\left(n_{3}\right)$ \\
\hline
\end{tabular}

When $z \downarrow 0, \theta_{1} \longrightarrow 1 /\left[1+2 \mu\left(n_{1}\right)\right]$ and $\theta_{3} \longrightarrow\left[1+2 \mu\left(n_{3}\right)\right]$. 
The properties stated in the proposition are intuitive. When the tastes for red goods are low in the sense that $\theta<\theta_{1}$, a buyer in a red trade does not spend all of his money. Since the legal restriction in the goods market does not bind in this case, bonds are perfect substitutes for money. When the tastes for red goods are high in the sense that $\theta>\theta_{3}$, a buyer in a red trade is constrained by the amount of his money holdings, but a buyer in a green trade is not constrained. Bonds are bad substitutes for money in this case. When the tastes for red goods are intermediate in the sense that $\theta_{1}<\theta<\theta_{3}$, the asset constraints bind in both a red and a green trade. Bonds are not perfect substitutes for money, but its substitutability for money is not as bad as in Case TS.

Bonds have different prices in the three cases, which reflect the difference in the substitutability of bonds for money. The Fisher equation holds only in Case TS, i.e., only if bonds do not generate any liquidity service in the goods market.

To conclude this section, let me remark that the conditions that $\gamma<\gamma_{0}$ and that $z$ is small are sufficient conditions for existence. They are imposed to ensure that the solution for $n$ is unique in each case. If $n$ were exogenous, then neither condition would be needed for existence or uniqueness of the equilibrium.

\section{Efficiency-Improving Role of the Legal Restriction}

In this section I take two steps to examine when the legal restriction can improve the society's welfare. First, for any fixed $\gamma \in\left(\beta, \gamma_{0}\right)$, where $\gamma_{0}$ is specified in Proposition 2.1, I show that the legal restriction can improve welfare. Second, I find a condition under which a deviation slightly above the Friedman rule is optimal. Under this condition, the optimal joint policy requires money growth that is higher than the Friedman rule and a legal restriction that distinguishes bonds from money in government liabilities. All proofs for this section appear in Appendix B. 


\subsection{Welfare Measure and the Way to Compare Economies}

Because the households are symmetric and there are no intrinsic dynamics, I measure social welfare in the standard way by the following steady-state utility:

$$
(1-\beta) v=\sum_{i=R, G}\left[\theta^{i} u\left(c^{i}\right)-\frac{\alpha N}{2} \psi\left(Q^{i}\right)\right]+h(1-n) .
$$

The legal restriction improves efficiency when it increases $v$.

To compare welfare, note that bonds are perfect substitutes for money in an economy without the legal restriction. If bonds are eliminated from such an economy, nominal prices of all goods will fall by the same proportion, leaving the real allocation unchanged. Thus, the real allocation in an economy without the legal restriction is the same as the allocation in an economy without bonds, provided that the money growth rate is fixed. For this reason, I will refer to the case $z=0$ as an economy without the legal restriction and to the effects of an increase in $z$ as the effects of the legal restriction.

Taking the limit $z \rightarrow 0$ in Proposition 2.1, I obtain the following allocation in an economy without the legal restriction: (A) If $\theta \leq(1+2 \mu)^{-1}$, then $q^{G}=q_{1}^{G}$ and $q^{R}=q_{1}^{R}$; (B) If $(1+2 \mu)^{-1}<\theta<1+2 \mu$, then $q^{G}=q^{R}=q_{2} \equiv f\left(\frac{2(1+\mu)}{1+\theta}, n\right)$; (C) If $\theta \geq 1+2 \mu$, then $q^{G}=q_{3}^{G}$ and $q^{R}=q_{3}^{R}$. Note that Case A has the same allocation as Case PS, and Case $\mathrm{C}$ has the same allocation as Case TS. That is, the legal restriction does not affect the real allocation when the tastes for the two types of goods are far from symmetric. For this reason, I will only compare Case IS with Case B.

\subsection{Effects of the Legal Restriction with Fixed Money Growth}

Let me first isolate the effects of the legal restriction by fixing money growth at $\gamma \in\left(\beta, \gamma_{0}\right)$. Consider the intensive margin of trade, represented by $q^{R}$ and $q^{G}$, and the extensive margin, $n$, which determines the number of trades. The following lemma documents the effects of the legal restriction on the two margins:

Lemma 3.1. For any fixed $\gamma \in\left(\beta, \gamma_{0}\right)$, a marginal increase in $z$ from $z=0$ increases $q_{2}^{G}$, reduces $q_{2}^{R}$, but it has no effect on $n$. 
The legal restriction increases the quantity of goods in a green trade and reduces the quantity in a red trade. It is easy to understand why the quantity of goods in a red trade falls: by depressing the purchasing power of both assets, the presence of bonds reduces the quantity of goods that can be purchased with money alone. To explain why the quantity of goods increases in a green trade, note that the purchasing power of assets falls by less than the increase in the amount of bonds, because the legal restriction prevents some of the bonds from being used to purchase goods. As a result, the real value of assets in a green trade increases, which increases the quantity of goods traded there. Therefore, the legal restriction shifts the purchasing power from red trades to green trades.

Prices do adjust to the increased amount of assets in the goods market. Express prices of goods in terms of utility, i.e., by multiplying prices by the value of money, $\omega^{m}$. After an increase in the amount of bonds, the price of green goods increases and the price of red goods falls. However, these responses of prices do not fully offset the shift of the purchasing power between the two types of trades.

On the extensive margin of trade, $n$, the legal restriction has no first-order effect, provided that money growth is constant. One way to explain this result is to note that the optimal choice of $n$ is determined by the expected marginal gain to a buyer. Because buyers are the individuals who carry money into trades, the expected marginal gain to a buyer is the non-pecuniary return to money, which must be equal to the opportunity cost of holding money. When money growth is fixed, the opportunity cost of holding money is unchanged, and so the optimal choice of $n$ does not change. Note that the legal restriction reduces the marginal gain to a buyer in a green trade as $q_{2}^{G}$ increases, and increases the marginal gain in a red trade as $q_{2}^{R}$ decreases. The constancy of $n$ with respect to $z$ means that these changes in the marginal gains exactly cancel out. That is, the legal restriction does not affect the expected sum of marginal utilities of the two goods.

However, the legal restriction does affect the expected level of utility, as stated below:

Proposition 3.2. Fix $\gamma \in\left(\beta, \gamma_{0}\right)$ and assume that $z$ is sufficiently small. The legal restriction improves efficiency if and only if $1 /(1+2 \mu)<\theta<1$. This region of $\theta$ is non-empty, provided $\gamma>\beta$. 
It is easy to explain this welfare effect. When $\theta<1$, the household has a stronger desire for green goods than for red goods. By shifting consumption from red goods to green goods, while keeping constant the expected sum of marginal utilities of the two goods, the legal restriction increases the expected level of utility. In this case, the legal restriction allows bonds to serve as partial insurance against the matching shocks. ${ }^{9}$ If $\theta>1$, on the other hand, the legal restriction reduces the expected utility.

The efficiency role of the legal restriction persists in the steady state and it does not require agents to be able to trade assets after observing the taste shocks. Both features are absent in Kocherlakota (2003). Moreover, because the legal restriction improves efficiency by shifting consumption between matches, it is important that the legal restriction is partial in the sense that it is imposed only in a fraction of trades. If the legal restriction were imposed universally, then the restriction would only reduce nominal prices of goods uniformly across all trades, in which case illiquid bonds would have no real effect.

For any $\gamma>\beta$, the efficiency role of the legal restriction exists in the specified region of $\theta$. However, the role disappears at the left border of the region, $\gamma=\beta$, which is the Friedman rule. When $\gamma=\beta$, a household is indifferent between spending a marginal unit of money and holding it to the next period. In this case, the constraints (2.3) and (2.4) do not bind, and the quantity of goods traded in a match equates the marginal utility of consumption to the marginal cost of production. In this sense, money provides perfect insurance against the matching shocks, and so it renders the legal restriction useless as a device of indirect insurance.

This dependence of the efficiency role on $\gamma>\beta$ is common in the literature. To justify $\gamma>\beta$, the literature has assumed that the social planner is not able to collect lump-sum taxes at all, e.g., Bryant and Wallace (1984) and Kocherlakota (2003). Because the above proposition requires only the weaker assumption that the social planner cannot implement the Friedman rule, one possible way to support the efficiency role of illiquid bonds is to rationalize this weaker assumption. A more challenging way is to find the condition under

\footnotetext{
${ }^{9}$ The condition $\theta>1 /(1+2 \mu)$ in the proposition comes from the existence condition for Case B. It is needed because the legal restriction affects the allocation only when both Case IS and Case B exist.
} 
which the Friedman rule is not optimal, as I will do below.

\subsection{The Efficiency Role of the Legal Restriction under Optimal Money Growth}

I first analyze the case $z=0$ and find a condition under which optimal money growth can exceed the Friedman rule. In this case, continuity implies that there exists a neighborhood of $z \geq 0$ in which a small deviation of money growth above the Friedman rule is optimal. Because Proposition 3.2 holds for all $\gamma \in\left(\beta, \gamma_{0}\right)$, there exists a neighborhood of $\theta<1$ such that the legal restriction improves efficiency under optimal money growth. Key to this result is the extensive margin of trade. Because this margin is immaterial in centralized markets, it is not surprising that the Friedman rule is optimal in traditional models such as Bryant and Wallace (1984) and Kocherlakota (2003).

Let me continue to focus on the case where the asset constraints bind in all trades. This is Case IS when $z>0$ and Case B when $z=0$. In Case B, $q_{2}^{G}=q_{2}^{R}=q_{2}$ and $(1+\theta) u^{\prime}\left(c_{2}\right)=2(1+\mu) \psi^{\prime}\left(q_{2}\right)$. Differentiating (2.12) with respect to $\gamma$ and evaluating the derivative at $z=0$ and $\gamma=\beta$, it can be verified that $[d n / d \gamma]_{\gamma=\beta}<0$ iff

$$
\frac{q_{0} \psi^{\prime}\left(q_{0}\right)}{\psi\left(q_{0}\right)}-1+k_{0} f_{1}\left(k_{0}, n\right) \frac{q_{0} \psi^{\prime \prime}\left(q_{0}\right)}{\psi\left(q_{0}\right)}<0,
$$

where $k_{0} \equiv 2 /(1+\theta)$ and $q_{0} \equiv f\left(k_{0}, n\right)$. Moreover,

$$
\frac{1-\beta}{\alpha}\left[\frac{d v}{d \gamma}\right]_{\gamma=\beta}=-\frac{\sigma}{n-\sigma}\left[q_{0} \psi^{\prime}\left(q_{0}\right)-\psi\left(q_{0}\right)\right]\left[\frac{d n}{d \gamma}\right]_{\gamma=\beta} .
$$

Because $q \psi^{\prime}>\psi$ for all $q>0$, welfare increases with $\gamma$ near $\gamma=\beta$ if and only if $n$ decreases with $\gamma$. This result, together with the argument in the first paragraph of this subsection, leads to the following proposition:

Proposition 3.3. A deviation slightly above the Friedman rule improves welfare if and only if it reduces the number of buyers in the goods market and, hence, if and only if (3.2) is satisfied. Therefore, under (3.2), there exists a neighborhood of $\theta<1$ where optimal monetary policy is $\gamma>\beta$ and where the legal restriction improves efficiency.

In contrast to the legal restriction, money growth affects the extensive margin of trade by affecting the gain from trade to a buyer. In turn, this effect can be decomposed into two 
effects. The first effect is negative: money growth reduces the quantity of goods traded in a match. The second effect is positive: by reducing consumption, money growth increases the marginal utility of consumption and hence increases the marginal value of goods received from a trade. These two effects work through the two terms in the summation of (2.12). The first effect dominates if and only if (3.2) is satisfied. Under this condition, the gain from trade and, hence, the number of buyers decreases with money growth.

Money growth also affects the intensive margin of trade, because it reduces the quantity of goods traded in a match. However, when $\gamma$ is close to $\beta$, this intensive margin has only a second-order effect on welfare, because the quantities of goods are close to the efficient ones that equate the marginal utility of consumption to the marginal cost of production. In this case, the extensive margin is the dominating margin of welfare.

An increase in money growth slightly above the Friedman rule improves welfare if and only if money growth reduces the number of buyers in the goods market. The explanation lies in search externalities generated by households' choices of $n$. Although the matching rates depend on $N$, and the equilibrium implies $N=n$, all households take the matching rates as given when choosing $n$. Thus, the equilibrium value of $N$ can be inefficient. The number of buyers in the equilibrium is inefficiently high if and only if buyers' bargaining power exceeds their contribution to the creation of matches (see Hosios, 1990). In the current model, a buyer in a trade takes the entire surplus of the match by assumption. To the number matches, $\alpha N$, the share contributed by buyers is:

$$
\frac{d \ln (\alpha N)}{d \ln (N-\sigma)}=\frac{N-\sigma}{N}<1
$$

That is, buyers are over-compensated and so the number of buyers is inefficiently high. Inflation can increase efficiency by reducing the number of buyers.

To see whether (3.2) can be satisfied, consider the functional forms $u(c)=\frac{c^{1-\eta}-1}{1-\eta}$ and $\psi(q)=\psi_{0} q^{\xi}$, where $\eta>0, \xi>1$ and $\psi_{0}>0$. Then, (3.2) is satisfied if and only if $\eta<1$.

The suboptimality of the Friedman rule is robust in the following two senses. First, it does not depend on the assumption that buyers have all the bargaining power in trade. If sellers have sufficiently high bargaining power, instead, then the measure of buyers can 
be inefficiently low rather than high, and efficiency entails an increase in the number of buyers. Although the condition (3.2) needs to be revised in this case, or even reversed, the general message remains true that optimal money growth can exceed the Friedman rule in a non-empty region of parameter values (see Shi, 1997, and Berentsen, Rocheteau and Shi, 2007). Second, the general message does not depend on the absence of direct taxes. After introducing direct (distortionary) taxes in a similar environment and setting them optimally, Ritter (2007) shows that optimal money growth can still exceed the Friedman rule. With these qualifications, the above proposition states the general possibility that the legal restriction can improve efficiency even under optimal monetary policy.

\section{Enforcement of the Legal Restriction}

I now address the issue of how to enforce the legal restriction. The proofs for this section are omitted here and can be found in the Supplementary Appendix.

Let me extend the basic model by adding a measure $g>0$ of government agents per household. To simplify the analysis, assume that all government agents are sellers. A government seller has the same disutility function of production as a private seller. The color of the good that a government seller can produce is determined by a random draw in each match, with probability $1 / 2$ for either color. Assume that only government sellers enforce the legal restriction in their trades and only when the good traded is red. In contrast, a (private) buyer can use both money and bonds as payments in any trade with other private agents or in a green trade with a government seller. Denote the fraction of sellers who are government agents as $\pi=g /(\sigma+g)$. Then, the legal restriction is enforced in a fraction $\pi / 2$ of the trades. For convenience, denote $\pi^{R}=\pi$ and $\pi^{G}=1-\pi$.

The total number of trade matches per household per period is $\alpha(N+g)$, and so the probability with which a buyer gets a trade match is $\alpha(N+g) /(N-\sigma)$. Conditional on receiving a trade match, a buyer's trading partner is a private seller with probability $(1-\pi)$ and a government seller with probability $\pi$. In either event, the good traded is red with probability $1 / 2$ and green with probability $1 / 2$. Add the superscripts $i j$ to the quantities of goods and money traded in a match, where $i \in\{G, R\}$ indicates the color of the good 
and $j \in\{p, g\}$ indicates whether the seller is a private seller $(p)$ or a government seller $(g)$. Then, a representative household's consumption of color $i$ good in a period is:

$$
c^{i}=\frac{\alpha(N+g)}{2(N-\sigma)}(n-\sigma)\left[(1-\pi) q^{i p}+\pi q^{i g}\right], \text { where } i \in\{G, R\} .
$$

Similarly, a private seller has a trade match with probability $\alpha(N+g) /(\sigma+g)$, and the trade involves either of the two colors with probability $1 / 2$. Because all buyers are private agents, a household's total disutility of production is:

$$
\frac{\alpha}{2}(N+g)(1-\pi)\left[\psi\left(Q^{G p}\right)+\psi\left(Q^{R p}\right)\right] .
$$

In each period, a household chooses $\left(q^{G p}, x^{G p}\right),\left(q^{R p}, x^{R p}\right),\left(q^{G g}, x^{G g}\right),\left(q^{R g}, x^{R g}\right), c^{G}, c^{R}$, $n$ and $\left(m_{+1}, b_{+1}\right)$. Similar to $(P H)$, the maximization problem is:

$$
v(m, b)=\max \left\{\sum_{i \in\{G, R\}}\left[\theta^{i} u\left(c^{i}\right)-\frac{\alpha}{2}(N+g)(1-\pi) \psi\left(Q^{i p}\right)\right]+h(1-n)+\beta v\left(m_{+1}, b_{+1}\right)\right\}
$$

where $c^{i}$ is given above, and the constraints are as follows:

$$
\begin{gathered}
x^{G j}=\frac{\psi\left(q^{G j}\right)}{\Omega^{m}} \leq \frac{m+b}{n-\sigma}, \text { for } j \in\{p, g\}, \\
x^{R p}=\frac{\psi\left(q^{R p}\right)}{\Omega^{m}} \leq \frac{m+b}{n-\sigma}, \\
x^{R g}=\frac{\psi\left(q^{R g}\right)}{\Omega^{m}} \leq \frac{m}{n-\sigma}, \\
m_{+1}+S_{+1} b_{+1}=\frac{1}{\gamma}(m+b)+T_{+1}+\frac{\alpha(N+g)}{2 \gamma}(1-\pi)\left(X^{G p}+X^{R p}\right) \\
-\frac{\alpha(N+g)}{2 \gamma} \frac{n-\sigma}{N-\sigma}\left[(1-\pi)\left(x^{G p}+x^{R p}\right)+\pi\left(x^{G g}+x^{R g}\right)\right] .
\end{gathered}
$$

To obtain (4.1) and (4.3), I have assumed that government sellers value money with the same marginal value $\Omega^{m}$ as private households do.

Focus on the case where money yields positive liquidity services at the margin in all trades that involve private sellers, i.e., the case where (4.1) binds for $j=p$ and (4.2) binds. Then, it can be shown that all the trading constraints in (4.1) - (4.3) bind. Moreover, in every trade without the legal restriction, the quantity of goods traded is equal to $q^{G}$, and the quantity of money traded is $x^{G}$. In a trade with the legal restriction, $q^{R g}$ is less than $q^{G}$ for all $z>0$ and equal to $q^{G}$ when $z=0$. 
Let me redefine the society's welfare to include the disutility of production incurred by government sellers, as well as the utility of private households. ${ }^{10}$ Let $v^{g}$ denote the discounted sum of expected disutility incurred by a government seller. Then,

$$
v^{g}=-\frac{1}{1-\beta} \frac{\alpha(n+g)}{2(\sigma+g)}\left[\psi\left(q^{G}\right)+\psi\left(q^{R g}\right)\right] .
$$

Let $v^{s}$ be the average value for an individual in the economy, which is obtained by giving the same weight to all individuals. All private households together have the weight $1 /(1+g)$, and all government sellers together have the weight $g /(1+g)$. Then, $v^{s}=\frac{1}{1+g} v+\frac{g}{1+g} v^{g}$. The legal restriction improves efficiency if it increases $v^{s}$. Substituting $v$ and $v^{g}$, I get:

$$
\begin{aligned}
(1+g)(1-\beta) v^{s}= & h(1-n)+u\left(c^{G}\right)+\theta u\left(c^{R}\right) \\
& -\alpha(n+g)\left[\left(1-\frac{\pi}{2}\right) \psi\left(q^{G}\right)+\frac{\pi}{2} \psi\left(q^{R g}\right)\right] .
\end{aligned}
$$

As in the basic model, I refer to the economy with $z=0$ as an economy without the legal restriction and to the effects of increasing $z$ as those of the legal restriction. ${ }^{11}$ Modify (2.14) to redefine the function $f(k, n)$ as follows:

$$
\frac{u^{\prime}\left(\frac{\alpha}{2}(n+g) f(k, n)\right)}{\psi^{\prime}(f(k, n))}=k .
$$

Define $q_{0}=f\left(k_{0}, n\right)$ as before, where $k_{0}=2 /(1+\theta)$. Then, I have:

Proposition 4.1. Proposition 3.3 continues to hold in this economy, where the legal restriction is enforced only in red trades that involve government sellers.

Although cumbersome to be analyzed, this extended model yields the same analytical results as the basic model. In particular, the same condition, (3.2), is needed for optimal money growth to be above the Friedman rule. The difference from the basic model is minor and quantitative, i.e., the modification of $f(k, n)$. The same intuition as in the basic model explains why the legal restriction on the liquidity of bonds can improve efficiency.

\footnotetext{
${ }^{10}$ The value of money received from trade by government sellers is not counted in the social welfare function because it is a transfer from the private sector to the government.

${ }^{11} \mathrm{It}$ is tempting to use the parameter $g$ as an alternative measure of the legal restriction and conduct comparative statics. Doing so is misleading because a change in $g$ changes the social welfare function even when the legal restriction is absent.
} 


\section{Discussion}

I discuss a few related issues. First, is the legal restriction "essential" in the sense that the social planner can achieve better allocations with the legal restriction than without? The answer is likely affirmative, provided that the social planner cannot observe the types of matches experienced by individuals. Although a formal support for this answer requires a setup of mechanism design, which is outside the scope this paper, I provide an informal argument as follows. The social planner needs to keep two reports of individuals' histories in order to allocate consumption and production efficiently. One is the report on whether an individual is a buyer or a seller in a match. To record this type of histories, the social planner can alter an individual's money holdings. Another report is on whether an individual has a red or green trade. Because the marginal utility of consumption depends on the color of the goods, it is efficient for the social planner to describe different quantities of goods to be traded in matches with different colors. To record this type of histories, the planner needs another asset. The legal restriction in my model implements this dependence of an individual's holdings of the second asset on the reported color of trade.

How can the second asset be interpreted as bonds, instead of any other asset? The answer lies in the particular distinction between the two types of histories. That is, the trades whose histories are recorded by the second asset in the planner's mechanism are a strict subset of the trades whose histories are kept by the first asset (money). Bonds with the legal restriction implement this distinction. In contrast, the distinction cannot be implemented with two kinds of monies whose relative acceptability is unrestricted. For example, suppose that the first money is green and the second money is red. These two monies can be designed to have different prices or even a fixed exchange rate. If both monies are accepted as payments in all trades, the price difference does not reflect any difference in acceptability. In this case, the holdings of the second money do not reflect any additional information about the color of trades that an agent has experienced. Of course, the social planner can elicit this information by making the red money unacceptable in red trades. But then the red money is equivalent to nominal bonds in my model; whether it is called 
bonds has no importance.

Second, one may want to distinguish the efficiency result in this paper from the general principle that introducing some distortions into an economy that already has imperfect markets can improve efficiency. Although the economy in my analysis is distorted with incomplete markets and bargaining, finding an additional distortion that can improve efficiency is not an easy task. In particular, introducing legal restrictions to generate return dominance has reduced efficiency in most models in the literature. For this reason, the result that the legal restriction can improve efficiency in my model is important.

Finally, one may ask why return dominance exists despite the apparent lack of legal restrictions on issuing private money. Introducing private money with small denominations will eliminate return dominance in Bryant and Wallace (1984), but not in my model. For example, suppose that private money is introduced into the economy as described in section 4. If the legal restriction requires government sellers not to accept private money in red trades, then private money must dominate fiat money in the rate of return, just as nominal bonds must. Put differently, private money will unlikely be essential in addition to fiat money and nominal bonds. Thus, the particular legal restriction in my model can provide a normative answer to the question of why private money is not widespread. ${ }^{12}$

\section{Conclusion}

In this paper, I examined whether a legal restriction that reduces the liquidity of nominal bonds can improve the society's welfare. To do so, I introduced nominal bonds and an asset market into a microfounded model of money. While the asset market is Walrasian, the goods market is decentralized, where the government imposes a legal restriction in a fraction of the trades. Individuals face matching shocks that affect the marginal utility of consumption, but they cannot insure, borrow or trade assets against such risks. I show that the partial legal restriction can improve efficiency of the economy by serving as

\footnotetext{
${ }^{12}$ After I wrote the first version of the current paper in 2002, I became aware of a paper by Rocheteau (2002), who uses a search model to examine the legal restriction in the goods market. His model is different from mine. Also, his result on the welfare-improving role of the legal restriction is largely numerical and he does not address the issue of how the legal restriction is enforced.
} 
partial insurance against the matching shocks. In contrast to some previous models (see the introduction), the efficiency role of the legal restriction persists in the steady state, and it does not require households to be able to trade bonds for money after receiving the shocks. Moreover, even when lump-sum taxes are available, the legal restriction can still improve welfare under a condition that induces optimal money growth to be above the Friedman rule. I have also examined the enforcement of the legal restriction.

As explained in the introduction, the current model will be useful for analyzing monetary policy, because it provides an efficiency role for return dominance that has been relied upon in all monetary policy analyses. In particular, the model can be extended to incorporate limited participation that captures the liquidity effect of open market operations (see Lucas, 1990). By providing a microfoundation for money and open market operations, such an extension will provide a justification for the liquidity effect on the basis of efficiency. It may also uncover new propagation mechanisms for monetary shocks. This task is left for a sequel. ${ }^{13}$ Another potential use of the current model is to examine whether there is an efficiency gain to restricting the circulation of foreign currency in a country. Such a restriction is similar to the legal restriction examined in the current paper.

\footnotetext{
${ }^{13}$ Williamson (2005) constructs a different model of limited participation to prolong the real effects of monetary injection. However, he does not examine the essentiality of illiquid bonds.
} 


\section{Appendix}

\section{A. Proof of Proposition 2.1}

The proof consists of three parts. Part 1: Given the solution for $n \in(\sigma, 1)$, I characterize each of the three cases. Part 2: Determine $n$ in each case. Part 3: Compare the $n$ 'es and $q$ 's among the three cases. While Parts 2 and 3 are relegated to the Supplementary Appendix in order to economize on space, Part 1 is detailed below.

For Case PS to occur, the quantities $\left(q_{1}^{R}, q_{1}^{G}\right)$ given by $(2.15)$ must induce $\lambda^{R}=0<\lambda^{G}$. That is, the asset constraints in trade must hold as follows: $\frac{1}{n-\sigma} \geq \frac{\psi\left(q_{1}^{R}\right)}{\omega^{m}}$ and $\frac{1+z}{n-\sigma}=\frac{\psi\left(q_{1}^{G}\right)}{\omega^{m}}$, where I have substituted the market clearing conditions $m=1$ and $b=z$. Combining the two constraints to eliminate $\omega^{m}$, I obtain the following condition for Case PS:

$$
q_{1}^{R}\left(n_{1}\right) \leq Q_{1}\left(n_{1}\right) \equiv \psi^{-1}\left(\frac{\psi\left(q_{1}^{G}\left(n_{1}\right)\right)}{1+z}\right) .
$$

Substituting $\left(q_{1}^{R}, q_{1}^{G}\right)$ from (2.15) and $f$ from (2.14), I rewrite (A.1) as $\theta \leq \theta_{1}$ where

$$
\theta_{1}=\Theta_{1}\left(n_{1}\right) \text { and } \Theta_{1}(n) \equiv \frac{\psi^{\prime}\left(Q_{1}(n)\right)}{u^{\prime}\left(\frac{\alpha n}{2} Q_{1}(n)\right)} .
$$

For all $z>0$ and $n \in(\sigma, 1), Q_{1}(n)<q_{1}^{G}(n)$ and so $\Theta_{1}(n)<[1+2 \mu(n)]^{-1}<1$. If $z \downarrow 0$, then $Q_{1}\left(n_{1}\right) \longrightarrow q_{1}^{G}\left(n_{1}\right)$, in which case (A.2) and (2.15) imply $\theta_{1} \longrightarrow 1 /\left[1+2 \mu\left(n_{1}\right)\right]$.

Similarly, examine Case TS, which requires $\lambda^{R}>0=\lambda^{G}$. That is, $\frac{1}{n-\sigma}=\frac{\psi\left(q_{3}^{R}\right)}{\omega^{m}}$ and $\frac{1+z}{n-\sigma} \geq \frac{\psi\left(q_{3}^{G}\right)}{\omega^{m}}$. Combining these two constraints yields:

$$
q_{3}^{R}\left(n_{3}\right) \geq Q_{3}\left(n_{3}\right) \equiv \psi^{-1}\left(\frac{\psi\left(q_{3}^{G}\left(n_{3}\right)\right)}{1+z}\right) .
$$

Substituting $\left(q_{3}^{R}, q_{3}^{G}\right)$ from (2.16) and $f$ from (2.14), I rewrite (A.3) as $\theta \geq \theta_{3}$ where

$$
\theta_{3}=\Theta_{3}\left(n_{3}\right) \text { and } \Theta_{3}(n) \equiv \frac{[1+2 \mu(n)] \psi^{\prime}\left(Q_{3}(n)\right)}{u^{\prime}\left(\frac{\alpha n}{2} Q_{3}(n)\right)} .
$$

For all $z>0$ and $n \in(\sigma, 1), Q_{3}(n)<q_{3}^{G}(n)$ and so $\Theta_{3}(n)<1+2 \mu(n)$. If $z \downarrow 0$, then $Q_{3}\left(n_{3}\right) \longrightarrow q_{3}^{G}\left(n_{3}\right)$, in which case (A.4) and (2.16) imply $\theta_{1} \longrightarrow 1 /\left[1+2 \mu\left(n_{1}\right)\right]$.

Now turn to Case IS. This case requires $\lambda^{R}$ and $\lambda^{G}$ to be positive. By (2.8), this requirement is equivalent to $\theta^{i} u^{\prime}\left(c_{2}^{i}\right)>\psi^{\prime}\left(q_{2}^{i}\right)$ for both $i=G$ and $i=R$. That is, $k^{G}>1$ 
and $k^{R}>1 / \theta$. Using (2.18), I can express these requirements as $\beta / \gamma<S<1$. Temporarily denote the left-hand side of (2.19) as $\operatorname{LHS}(S, n)$. For any given $n \in(\sigma, 1), k^{G}(S, n)$ increases in $S$ and $k^{R}(S, n)$ decreases in $S$. Because $f(k, n)$ is decreasing in $k$, then $Q_{2}^{G}(S, n)$ decreases in $S$ and $Q_{2}^{R}(S, n)$ increases in $S$. Thus, $\operatorname{LHS}(S, n)$ decreases in $S$ for any given $n \in(\sigma, 1)$. Moreover, because $Q_{2}^{G}(\beta / \gamma, n)=q_{3}^{G}(n)$ and $Q_{2}^{R}(\beta / \gamma, n)=q_{3}^{R}(n)$, then $L H S(\beta / \gamma, n)>0$ iff $q_{3}^{R}(n)<Q_{3}(n)$, i.e., iff $\theta<\Theta_{3}(n)$. Similarly, because $Q_{2}^{G}(1, n)=$ $q_{1}^{G}(n)$ and $Q_{2}^{R}(1, n)=q_{1}^{R}(n)$, then $\operatorname{LHS}(1, n)<0$ iff $q_{1}^{R}(n)>Q_{1}(n)$, i.e., iff $\theta>\Theta_{1}(n)$. It can be shown that $n_{2} \rightarrow n_{3}$ when $S \rightarrow \beta / \gamma$, and that $n_{2} \rightarrow n_{1}$ when $S \rightarrow 1$. Therefore, Case IS exists iff $\theta_{1}=\Theta_{1}\left(n_{1}\right)<\theta<\Theta_{3}\left(n_{3}\right)=\theta_{3}$.

To show that $\theta_{1}<\theta_{3}$ holds, note that, when $z=0$, I have $\Theta_{1}(n)=[1+2 \mu(n)]^{-1}$ and $\Theta_{3}(n)=1+2 \mu(n)$. Thus, for all $\gamma>\beta$ and all $n, n^{\prime} \in(\sigma, 1)$, I have $\Theta_{1}(n)<\Theta_{3}\left(n^{\prime}\right)$. This implies $\theta_{1}<\theta_{3}$ when $z$ is sufficiently small. QED

\section{B. Proofs for Section 3}

Let me start with the proof of Lemma 3.1. Denote the derivative of $f(k, n)$ to the $j$ th argument as $f_{j}$, where $f$ is defined in (2.14). Then, $f_{1}<0$ and $f_{2}<0$. All the derivatives below with respect to $z$ are evaluated at $z=0$, and the notation for this evaluation is suppressed. Recall that, when $z=0, q_{2}^{G}=q_{2}^{R}=q_{2}=f(k, n)$, where $k=2(1+\mu) /(1+\theta)$. Differentiating (2.18) and (2.19) with respect to $z$ and evaluating at $z=0$ yields:

$$
\begin{gathered}
\frac{d q_{2}^{i}}{d z}=f_{1} \frac{d k^{i}}{d z}+f_{2} \frac{d n}{d z}, \text { for } i=G, R, \\
\frac{\psi}{f_{1} \psi^{\prime}}=\frac{d q_{2}^{G}}{d z}-\frac{d q_{2}^{R}}{d z},
\end{gathered}
$$

where $k^{i}$ is defined in (2.17) and where the argument of $\psi$ and $\psi^{\prime}$ is $q_{2}$. Use the two results above and substitute $d k^{i} / d z$ to solve for $d S / d z$. Then,

$$
\frac{d k^{G}}{d z}=\frac{1}{1+\theta}\left(\theta \frac{\psi}{f_{1} \psi^{\prime}}+2 \frac{d \mu}{d z}\right), \quad \theta \frac{d k^{R}}{d z}+\frac{d k^{G}}{d z}=2 \frac{d \mu}{d z} .
$$

Note that $f_{1}<0$ and $\frac{d \mu}{d z}=\frac{\sigma}{\alpha n^{2}}\left(\frac{\gamma}{\beta}-1\right) \frac{d n}{d z}$. If $d n / d z=0$, as stated in Lemma 3.1, then $d k^{G} / d z<0$ and $d k^{R} / d z>0$. In this case, (B.1) implies $d q_{2}^{G} / d z>0$ and $d q_{2}^{R} / d z<0$. 
To show $d n / d z=0$, substitute $u^{\prime}\left(c_{2}^{i}\right)=k^{i} \psi^{\prime}\left(q_{2}^{i}\right)$ to rewrite $(2.12)$ as:

$$
\frac{2(n-\sigma)}{\alpha n} h^{\prime}=\theta k^{R}\left[q_{2}^{R} \psi^{\prime}\left(q_{2}^{R}\right)-\psi\left(q_{2}^{R}\right)\right]+k^{G}\left[q_{2}^{G} \psi^{\prime}\left(q_{2}^{G}\right)-\psi\left(q_{2}^{G}\right)\right] .
$$

Differentiating this equation with respect to $z$, evaluating at $z=0$, and substituting $d q / d z$ and $d k^{i} / d z$, I obtain $d n / d z=0$. This completes the proof of Lemma 3.1.

To prove Proposition 3.2, differentiate the welfare measure in (3.1) with respect to $z$, evaluate at $z=0$, and substitute the above derivatives of $\left(q_{2}^{R}, q_{2}^{G}, n\right)$. Then,

$$
\frac{1-\beta}{\alpha n} \frac{d v}{d z}=\frac{(1-\theta) \psi\left(q_{2}\right)}{2(1+\theta)}
$$

$d v / d z>0$ if and only if $\theta<1$. Since this effect exists only if Case IS and Case B both exist, $\theta>\left[1+2 \mu\left(n_{1}\right)\right]^{-1}$ is required. Thus, when $\left[1+2 \mu\left(n_{1}\right)\right]^{-1}<\theta<1$ and when $z$ is small, $d v / d z>0$ for all $\gamma \in\left(\beta, \gamma_{0}\right)$. Finally, this region of $\theta$ is non-empty if and only if $\mu\left(n_{1}\right)>0$, which is equivalent to $\gamma>\beta$. QED 


\section{References}

[1] Aiyagari, R., Wallace, N., Wright, R., 1996. Coexistence of money and interest-bearing securities. Journal of Monetary Economics 37, 397-419.

[2] Andolfatto, D., 2006. Revisiting the legal-restriction hypothesis. Manuscript, Simon Fraser University.

[3] Berentsen, A., Camera, G., Waller, C., 2007. Money, credit and banking. Journal of Economic Theory 135, 171-195.

[4] Berentsen, A., Rocheteau, G., Shi, S., 2007. Friedman meets Hosios: efficiency in search models of money. Economic Journal 117, 174-195.

[5] Boel, P., Camera, G., 2006. Efficient monetary allocations and the illiquidity of bonds. Journal of Monetary Economics 53, 1693-1715.

[6] Bryant, J., Wallace, N., 1984. A price discrimination analysis of monetary policy. Review of Economic Studies 51, 279-288.

[7] Hicks, J.R., 1939. Value and Capital: An Inquiry into Some Fundamental Principles of Economic Theory. Clarendon Press, Oxford, pp.163-170.

[8] Hosios, A., 1990. On the efficiency of matching and related models of search unemployment. Review of Economic Studies 57, 279-298.

[9] Kocherlakota, N., 2003. Societal benefits of illiquid bonds. Journal of Economic Theory 108, 179-193.

[10] Lagos, R., Wright, R., 2005. A unified framework for monetary theory and policy analysis. Journal of Political Economy 113, 463-84.

[11] Lucas Jr., R.E., 1990. Liquidity and interest rates. Journal of Economic Theory 50, $237-264$. 
[12] Ritter, M., 2007. The optimum quantity of money revisited: distortionary taxation in a search model of money. Manuscript, University of Toronto.

[13] Rocheteau, G., 2002. On the existence of nominal government bonds and money. Manuscript, National University of Australia.

[14] Shi, S., 1997. A divisible search model of fiat money. Econometrica 65, 75-102.

[15] Shi, S., 2001. Liquidity, bargaining, and multiple equilibria in a search monetary model. Annals of Economics and Finance 2, 325-351.

[16] Shi, S., 2005. Nominal bonds and interest rates. International Economic Review 46, 579-618.

[17] Sun, L., 2005. Sustained societal benefit of illiquid bonds. Manuscript, University of Toronto.

[18] Temzelides, T., Williamson, S., 2001. Payments systems design in deterministic and private information environments. Journal of Economic Theory 99, 2001.

[19] Wallace, N., 1983. A legal restrictions theory of the demand for 'money' and the role of monetary policy. Federal Reserve Bank of Minneapolis Quarterly Review 7, 1-7.

[20] Williamson, S., 2005. Monetary policy and distribution. Manuscript, University of Iowa. 


\section{Not for Publication:}

\section{Supplementary Appendix for "Efficiency Improvement from Restricting the Liquidity of Nominal Bonds"}

by Shouyong Shi

\section{Parts 2 and 3 of the Proof of Proposition 2.1}

Part 2. Determine $n$ in each case. In Case PS, substitute $u^{\prime}\left(c_{1}^{G}\right)=(1+2 \mu) \psi^{\prime}\left(q_{1}^{G}\right)$ and $\theta u^{\prime}\left(c_{1}^{R}\right)=\psi^{\prime}\left(q_{1}^{R}\right)$ to rewrite $(2.12)$ as

$$
\frac{2 h^{\prime}(1-n)}{\frac{\alpha n}{n-\sigma}[1+2 \mu(n)]}=\left[q_{1}^{G}(n) \psi^{\prime}\left(q_{1}^{G}(n)\right)-\psi\left(q_{1}^{G}(n)\right)\right]+\frac{q_{1}^{R}(n) \psi^{\prime}\left(q_{1}^{R}(n)\right)-\psi\left(q_{1}^{R}(n)\right)}{1+2 \mu(n)} .
$$

Note that the expression $\frac{\alpha n}{n-\sigma}[1+2 \mu(n)]$ is a decreasing function of $n$, and so the left-hand side of this equation increases in $n$. Because $\mu(n)$ decreases in $n$, and $q_{1}^{G}(n)$ and $q_{1}^{R}(n)$ both decrease in $n$, the right-hand side of the equation decreases in $n$. The solution for $n$ to the equation is unique if it exists. Existence can be verified with the assumptions on $(h, u, \psi)$. Denote the solution as $n_{1} \in(\sigma, 1)$.

Similarly, in Case TS, I can rewrite (2.12) as

$$
\frac{2 h^{\prime}(1-n)}{\frac{\alpha n}{n-\sigma}[1+2 \mu(n)]}=\left[q_{3}^{R}(n) \psi^{\prime}\left(q_{3}^{R}(n)\right)-\psi\left(q_{3}^{R}(n)\right)\right]+\frac{q_{3}^{G}(n) \psi^{\prime}\left(q_{3}^{G}(n)\right)-\psi\left(q_{3}^{G}(n)\right)}{1+2 \mu(n)}
$$

and show that that a unique solution exists. Denote the solution as $n_{3} \in(\sigma, 1)$.

Denote the equilibrium value of $n$ in Case IS as $n_{2}$, and the solution for $S$ to (2.19) as $S(n)$. To determine $n_{2}$, denote:

$$
k^{* i}(n)=k^{i}(S(n), n), q_{2}^{i}(n)=Q_{2}^{i}(S(n), n) \text {, where } i=G, R .
$$

Then, (2.12) in Case IS can be rewritten as follows:

$$
h^{\prime}(1-n)=\sum_{i=G, R} \frac{\alpha n k^{* i}(n)}{2(n-\sigma)} \theta^{i}\left[q_{2}^{i}(n) \psi^{\prime}\left(q_{2}^{i}(n)\right)-\psi\left(q_{2}^{i}(n)\right)\right] .
$$

I establish first existence and uniqueness of the solution to this equation when $z=0$. When $z=0$, the solution $S(n)$ to $(2.19)$ yields $q_{2}^{G}(n)=q_{2}^{R}(n)$ and hence $k^{* G}(n)=$ 
$k^{* R}(n)$. Differentiating (2.19) with respect to $n$ to obtain $S^{\prime}(n)$, I can compute the following derivatives at $z=0$ for both $i=G$ and $i=R$ :

$$
\frac{d k^{* i}(n)}{d n}=\frac{2(\gamma / \beta-1) \sigma}{(1+\theta) \alpha n^{2}}>0 ; \quad \frac{d q^{i}(n)}{d n}=f_{1} \frac{d k^{* i}(n)}{d n}+f_{2}<0
$$

Using these results, I can compute further:

$$
\frac{d}{d n}\left[\frac{\alpha n k^{* i}(n)}{2(n-\sigma)}\right]=\frac{\sigma}{(1+\theta) n(n-\sigma)}\left[(1-S(n)) \frac{\gamma}{\beta}-\theta\left(\frac{\gamma}{\beta} S(n)-1\right)-\frac{\alpha n(1+\theta)}{2(n-\sigma)}\right] .
$$

Note that the expression inside [.] decreases in $S$. Since $S \geq \beta / \gamma$ and $n>n-\sigma$, I can show that the expression is less than $\left(\gamma-\gamma_{0}\right) / \beta$, where $\gamma_{0}$ is defined in Proposition 2.1. If $\gamma \in\left(\beta, \gamma_{0}\right)$, the above derivative is negative, in which case the right-hand side of (C.4) decreases in $n$. Because the left-hand side increases in $n$, the solution to (C.4) is unique if $\gamma \in\left(\beta, \gamma_{0}\right)$ and $z=0$. Existence of the solution follows from the assumptions on $(h, u, \psi)$.

Since the solution is continuous in $z$ in a neighborhood of $z=0$, then the solution to (C.4) exists and is unique if $\gamma \in\left(\beta, \gamma_{0}\right)$ and if $z$ is sufficiently small.

Part 3. Compare the $n$ 'es and $q$ 's among the three cases. First, I show that $n_{1}<n_{3}$. For any fixed $n \in(\sigma, 1)$, the following result holds:

$$
q_{1}^{R}(n)=f\left(\frac{1}{\theta}, n\right) \leq f\left(\frac{1}{\theta_{1}}, n\right)<q_{3}^{G}(n)=f(1, n) .
$$

The first inequality comes from the facts that $\theta \leq \theta_{1}$ in Case PS and that $f(k, n)$ decreases in $k$. The second inequality comes from the fact that $\theta_{1} \leq 1 /\left[1+2 \mu\left(n_{1}\right)\right]<1$. Moreover, because $\Theta_{3}(n)=1+2 \mu(n)$ when $z=0$, then $\theta_{3}>1$ when $z$ is sufficiently small. For any fixed $n \in(\sigma, 1)$ and for sufficiently small $z$, I have:

$$
q_{1}^{G}(n)<f\left(\frac{1+2 \mu(n)}{\theta_{3}}, n\right) \leq q_{3}^{R}(n)=f\left(\frac{1+2 \mu(n)}{\theta}, n\right) .
$$

The first equality comes from $\theta_{3}>1$, and the second inequality from $\theta \geq \theta_{3}$ in Case TS. Thus, for sufficiently small $z$ and for any fixed $n \in(\sigma, 1)$, the right-hand side of (C.1) is strictly smaller than that of (C.2). As a result, $n_{1}<n_{3}$ when $z$ is small.

Second, I show that $n_{1}<n_{2}<n_{3}$. With $k^{* i}$ defined in (C.3), I have:

$$
\frac{\alpha n k^{* G}(n)}{2(n-\sigma)}=\frac{\alpha n}{2(n-\sigma)}+\frac{\gamma}{\beta} S(n)-1
$$




$$
\frac{\theta \alpha n k^{* R}(n)}{2(n-\sigma)}=\frac{\alpha n}{2(n-\sigma)}+\frac{\gamma}{\beta}[1-S(n)]
$$

If I substitute these expressions and $q_{2}^{i}(n)=Q_{2}^{i}(S(n), n)$ into (C.4) and treat $S$ as a separate variable, then the right-hand side of (C.4) becomes a decreasing function of $S$ at $z=0$. When $S \rightarrow \beta / \gamma$, (C.4) becomes (C.2), and so $n_{2} \rightarrow n_{3}$. When $S \rightarrow 1$, (C.4) becomes (C.1), and so $n_{2} \rightarrow n_{1}$. This procedure also shows that $n_{1}<n_{2}<n_{3}$ when $z$ is sufficiently small.

Third, I compare $q_{1}^{R}\left(n_{1}\right)$ with $q_{3}^{R}\left(n_{3}\right)$. Consider the case $z=0$. In this case, $\Theta_{3}(n)=$ $1+2 \mu(n)$. For all $\theta \geq \theta_{3}$,

$$
\frac{1+2 \mu\left(n_{3}\right)}{\theta} \leq \frac{1+2 \mu\left(n_{3}\right)}{\theta_{3}}=1
$$

This implies $q_{3}^{R}\left(n_{3}\right) \geq q_{3}^{G}\left(n_{3}\right)$, which further implies:

$$
q_{3}^{R}\left(n_{3}\right) \psi^{\prime}\left(q_{3}^{R}\left(n_{3}\right)\right)-\psi\left(q_{3}^{R}\left(n_{3}\right)\right) \geq\left.\frac{1+2 \mu\left(n_{3}\right)}{2\left[1+\mu\left(n_{3}\right)\right]} R H S(\text { C. } 2)\right|_{n=n_{3}}=\frac{h\left(1-n_{3}\right)}{\frac{\alpha n_{3}}{n_{3}-\sigma}\left[1+\mu\left(n_{3}\right)\right]} .
$$

The equality comes from (C.2). Similarly, when $z=0, q_{1}^{R}\left(n_{1}\right) \leq q_{1}^{G}\left(n_{1}\right)$ and so

$$
q_{1}^{R}\left(n_{1}\right) \psi^{\prime}\left(q_{1}^{R}\left(n_{1}\right)\right)-\psi\left(q_{1}^{R}\left(n_{1}\right)\right) \leq\left.\frac{1+2 \mu\left(n_{1}\right)}{2\left[1+\mu\left(n_{1}\right)\right]} R H S(\text { C. } 1)\right|_{n=n_{1}}=\frac{h\left(1-n_{1}\right)}{\frac{\alpha n_{1}}{n_{1}-\sigma}\left[1+\mu\left(n_{1}\right)\right]} .
$$

Because the function $\frac{n}{n-\sigma}[1+\mu(n)]$ decreases in $n$, the last expression increases in $n$. Since $n_{1}<n_{3}$ when $z=0$, then

$$
q_{3}^{R}\left(n_{3}\right) \psi^{\prime}\left(q_{3}^{R}\left(n_{3}\right)\right)-\psi\left(q_{3}^{R}\left(n_{3}\right)\right) \geq q_{1}^{R}\left(n_{1}\right) \psi^{\prime}\left(q_{1}^{R}\left(n_{1}\right)\right)-\psi\left(q_{1}^{R}\left(n_{1}\right)\right) .
$$

This implies $q_{3}^{R}\left(n_{3}\right)>q_{1}^{R}\left(n_{1}\right)$ when $z=0$ and, hence, when $z$ is sufficiently small.

A similar procedure, together with the facts that $S \in(\beta / \gamma, 1)$ and $n_{2} \in\left(n_{1}, n_{3}\right)$, leads to the result that $q_{1}^{R}\left(n_{1}\right)<q_{2}^{R}\left(n_{2}\right)<q_{3}^{R}\left(n_{3}\right)$. QED

\section{Derivations and Proofs for Section 4}

In this appendix, I characterize the equilibrium of the economy described in section 4 and prove Proposition 4.1. Start with the household's optimization problem in section 4. Let $\lambda^{G j}$ be the Lagrangian multiplier of (4.1), $\lambda^{R p}$ of (4.2), and $\lambda^{R g}$ of (4.3). These multipliers 
are multiplied by the number of the corresponding trades before being incorporated into the Lagrangian of the maximization problem. Similar to (2.8), I can derive the first-order condition of $q^{i j}$ as:

$$
\theta^{i} u^{\prime}\left(c^{i}\right)=\frac{\omega^{m}+\lambda^{i j}}{\Omega^{m}} \psi^{\prime}\left(q^{i j}\right), \text { where } i \in\{G, R\} \text { and } j \in\{p, g\} .
$$

To proceed, let me establish the following lemma:

Lemma D.1. (i) Either $\lambda^{G p}>0$ and $\lambda^{G g}>0$, or $\lambda^{G P}=\lambda^{G g}=0$; (ii) $\lambda^{G g}=\lambda^{G p} \equiv \lambda^{G}$, $x^{G g}=x^{G p} \equiv x^{G}$ and $q^{G g}=q^{G p} \equiv q^{G}$; (iii) for all $z>0$, the equilibrium generates $\lambda^{R p} \leq \lambda^{R g}, x^{R p} \geq x^{R g}$ and $q^{R p} \geq q^{R g}$, with equality if and only if $\lambda^{R g}=0\left(=\lambda^{R p}\right)$.

Proof. To prove (i), suppose first that $\lambda^{G p}>0$. Then, $x^{G p}=(m+b) /(n-\sigma) \geq x^{G g}$. This result and (4.1) together imply $\psi\left(q^{G p}\right) \geq \psi\left(q^{G g}\right)$, and so $q^{G p} \geq q^{G g}$. Substituting the last result into (D.1) (for $i=G$ ) and invoking symmetry of the equilibrium, I get:

$$
\frac{\lambda^{G g}}{\Omega^{m}}+1=\frac{u^{\prime}\left(c^{G}\right)}{\psi^{\prime}\left(q^{G g}\right)} \geq \frac{u^{\prime}\left(c^{G}\right)}{\psi^{\prime}\left(q^{G p}\right)}=\frac{\lambda^{G p}}{\Omega^{m}}+1 .
$$

That is, $\lambda^{G g} \geq \lambda^{G p}$. Thus, $\lambda^{G p}>0$ implies $\lambda^{G g}>0$. Similarly, $\lambda^{G g}>0$ implies $\lambda^{G p}>0$.

For (ii), consider first the case $\lambda^{G p}>0$ and $\lambda^{G g}>0$. Then (4.1) binds for both $j=p$ and $j=g$. These binding constraints immediately yield $q^{G p}=q^{G g}$ and $x^{G p}=x^{G g}$. Then, (D.1) for $i=G$ yields $\lambda^{G p}=\lambda^{G g}$. By (i) above, the only remaining case to be considered is $\lambda^{G p}=\lambda^{G g}=0$. In this case, (D.1) for $i=G$ implies $q^{G p}=q^{G g}$, and the equality part of (4.1) implies $x^{G p}=x^{G g}$.

For (iii), suppose first that $\lambda^{R p}>0$. Then,

$$
x^{R p}=\frac{m+z}{n-\sigma}>\frac{m}{n-\sigma} \geq x^{R g},
$$

where the first (strict) inequality follows from the assumption $z>0$. With (4.2) and (4.3), the above result implies $\psi\left(q^{R p}\right)>\psi\left(q^{R g}\right)$ and so $q^{R p}>q^{R g}$. Then, (D.1) for $i=R$ implies $\lambda^{R p}<\lambda^{R g}$, as stated above. Now suppose $\lambda^{R p}=0$. If $\lambda^{R g}=0$ as well, then (D.1) for $i=R$ implies $q^{R p}=q^{R g}$. In this case, (4.2) and (4.3) imply $x^{R p}=x^{R g}$. If $\lambda^{R g}>0$ (but $\lambda^{R p}=0$ ), then (D.1) for $i=R$ implies:

$$
\frac{\theta u^{\prime}\left(c^{R}\right)}{\psi^{\prime}\left(q^{R p}\right)}-1=0<\frac{\lambda^{R g}}{\omega^{m}}=\frac{\theta u^{\prime}\left(c^{R}\right)}{\psi^{\prime}\left(q^{R g}\right)}-1 .
$$


That is, $q^{R p}>q^{R g}$. In this case, (4.2) and (4.3) imply $x^{R p}>x^{R g}$. QED

As stated in the main text, let me focus on the case where $\lambda^{G p}>0$ and $\lambda^{R p}>0$. Then, Lemma D.1 implies that $\lambda^{G g}>0$ and $\lambda^{R g}>0$. That is, all the trading constraints in (4.1) - (4.3) bind. Moreover, $x^{G g}=x^{G p} \equiv x^{G}$ and $q^{G g}=q^{G p} \equiv q^{G}$. Furthermore, with $\lambda^{G}>0$ and $\lambda^{R p}>0$, (4.1) and (4.2) imply:

$$
\frac{\psi\left(q^{G}\right)}{\Omega^{m}}=x^{G}=\frac{m+b}{n-\sigma}=x^{R p}=\frac{\psi\left(q^{R p}\right)}{\Omega^{m}} .
$$

This result yields $q^{R p}=q^{G}$.

In a trade where the legal restriction is enforced, the quantity of (red) goods traded can be obtained from the binding constraints, (4.2) and (4.3), as follows:

$$
q^{R g}=q^{R G}\left(q^{G}\right) \equiv \psi^{-1}\left(\frac{\psi\left(q^{G}\right)}{1+z}\right),
$$

where I have used the fact that $b=z$ in the equilibrium. Similarly, I can express the representative household's consumption levels of the two colors as functions of $q^{G}$ and $N$ :

$$
c^{G}\left(q^{G}, N\right)=\frac{\alpha}{2}(N+g) q^{G}, \quad c^{R}\left(q^{G}, N\right)=\frac{\alpha}{2}(N+g)\left[(1-\pi) q^{G}+\pi q^{R g}\left(q^{G}\right)\right] .
$$

Note that $q^{R g}<q^{G}$ and $c^{R}<c^{G}$ for all $z>0$. Also, $q^{R g} \uparrow q^{G}$ and $c^{R} \uparrow c^{G}$ as $z \downarrow 0$.

In the symmetric equilibrium, $Q=q$ and $N=n$. Two conditions determine $q^{G}$ and $n$ in the equilibrium. The first is the envelope condition for money holdings. Deriving this condition and using (D.1) to substitute the $\lambda$ 'es, I get:

$$
2[1+\mu(n)]=\frac{u^{\prime}\left(c^{G}\right)}{\psi^{\prime}\left(q^{G}\right)}+\theta u^{\prime}\left(c^{R}\right)\left[\frac{1-\pi}{\psi^{\prime}\left(q^{G}\right)}+\frac{\pi}{\psi^{\prime}\left(q^{R g}\left(q^{G}\right)\right)}\right],
$$

where $\mu(n)$ is defined as

$$
\mu(n) \equiv \frac{n-\sigma}{\alpha(n+g)}\left(\frac{\gamma}{\beta}-1\right) .
$$

The other condition is the first-order condition of $n$ which, under symmetry, is:

$$
\begin{aligned}
\frac{2(n-\sigma)}{\alpha(n+g)} h^{\prime}= & \pi \frac{\theta u^{\prime}\left(c^{R}\right)}{\psi^{\prime}\left(q^{R g}\right)}\left[q^{R g} \psi^{\prime}\left(q^{R g}\right)-\psi\left(q^{R g}\right)\right] \\
& {\left[2(1+\mu(n))-\pi \frac{\theta u^{\prime}\left(c^{R}\right)}{\psi^{\prime}\left(q^{R g}\right)}\right]\left[q^{G} \psi^{\prime}\left(q^{G}\right)-\psi\left(q^{G}\right)\right] . }
\end{aligned}
$$

Now I find the restrictions on $\theta$ which support the current case to be the equilibrium, i.e., the case with $\lambda^{G}>0$ and $\lambda^{R p}>0$. The restriction $\lambda^{G}>0$ is equivalent to $u^{\prime}\left(c^{G}\right) / \psi^{\prime}\left(q^{G}\right)>$ 
1 (see (D.1)). Using the function $f(k, n)$ defined in (4.5), I rewrite this restriction as $q^{G}<f(1, n)$. Because the right-hand side of (D.4) is a decreasing function of $q^{G}$, then $q^{G}<f(1, n)$ if and only if $2(1+\mu)>\left.\operatorname{RHS}(\mathrm{D} .4)\right|_{q^{G}=f(1, n)}$. Rewrite this condition as $\theta<\Theta_{3}(n)$, where $\Theta_{3}$ is redefined as follows:

$$
\Theta_{3}(n) \equiv \frac{1+2 \mu(n)}{\left[u^{\prime}\left(c^{R}\left(q^{G}, n\right)\right)\left(\frac{1-\pi}{\psi^{\prime}\left(q^{G}\right)}+\frac{\pi}{\psi^{\prime}\left(q^{R g}\left(q^{G}\right)\right)}\right)\right]_{q^{G}=f(1, n)}} .
$$

The restriction $\lambda^{R p}>0$ is equivalent to $\theta>\psi^{\prime}\left(q^{G}\right) / u^{\prime}\left(c^{R}\right)$ (see (D.1)). Use (D.4) to rewrite this condition as:

$$
2[1+\mu(n)]>\frac{u^{\prime}\left(c^{G}\left(q^{G}, n\right)\right)}{\psi^{\prime}\left(q^{G}\right)}+1-\pi+\pi \frac{\psi^{\prime}\left(q^{G}\right)}{\psi^{\prime}\left(q^{R g}\left(q^{G}\right)\right)} .
$$

Under mild assumptions, the right-hand side of the above inequality is a decreasing function of $q^{G}$. Let $\hat{q}(n)$ be the solution for $q^{G}$ to the equality form of the above relation. Then, $\lambda^{R p}>0$ if and only if $q^{G}>\hat{q}(n)$. Denote $\hat{q}^{R g}(n)=q^{R G}(\hat{q}(n))$ and $\hat{c}^{i}(n)=c^{i}(\hat{q}(n), n)$, where $i \in\{G, R\}$. Then, (D.4) implies that $q^{G}>\hat{q}(n)$ if and only if $\theta>\Theta_{1}(n)$, where

$$
\Theta_{1}(n) \equiv \frac{2[1+\mu(n)]-u^{\prime}\left(\hat{c}^{G}(n)\right) / \psi^{\prime}(\hat{q}(n))}{u^{\prime}\left(\hat{c}^{R}(n)\right)\left[\frac{1-\pi}{\psi^{\prime}(\hat{q}(n))}+\frac{\pi}{\psi^{\prime}\left(\hat{q}^{R g}(n)\right)}\right]} .
$$

Therefore, the focused case occurs if and only if $\Theta_{1}(n)<\theta<\Theta_{3}(n)$. Note that when $z \downarrow 0$, $\Theta_{1}(n) \longrightarrow 1 /(1+2 \mu)$ and $\Theta_{3}(n) \longrightarrow 1+2 \mu$. Thus, for small $z>0$, the interior of the interval $\left(\Theta_{1}(n), \Theta_{3}(n)\right)$ is non-empty for all $\gamma>\beta$ and contains the value 1 .

Now I prove Proposition 4.1. As in the proof of Proposition 3.3, I first find the condition under which optimal money growth is $\gamma>\beta$. Then, given any $\gamma>\beta$, I show that increasing $z$ from 0 to a slightly positive number increases social welfare.

Examine first the effects of money growth at $z=0$. When $z=0$, the above analysis implies $q^{R g}=q^{G}$ and $c^{R}=c^{G}$. Denote the common level of the $q^{\text {'s }}$ as $q$ and the common level of the $c^{\prime}$ es as $c$. Then, at $z=0,(D .4)$ and (D.6) become:

$$
\begin{gathered}
q=f(k, n) \quad \text { where } k=\frac{2(1+\mu)}{1+\theta}, \\
\frac{n-\sigma}{\alpha(n+g)} h^{\prime}(1-n)=[1+\mu(n)]\left[q \psi^{\prime}(q)-\psi(q)\right] .
\end{gathered}
$$


Also, the welfare measure in (4.4) simplifies to:

$$
(1+g)(1-\beta) v^{s}=(1+\theta) u(c)-\alpha(n+g) \psi(q)+h .
$$

Differentiating (D.5) and the three equations above with respect to $\gamma$ and evaluating the derivatives at $\gamma=\beta$, it can be shown that

$$
\left[\frac{d v^{s}}{d \gamma}\right]_{\gamma=\beta, z=0}>0 \Longleftrightarrow\left[\frac{d n}{d \gamma}\right]_{\gamma=\beta, z=0}<0 \Longleftrightarrow(3.2) .
$$

Now examine the effects of the legal restriction, captured by the effects of $z$. Fix $\gamma$ at an arbitrary level above $\beta$. Differentiating (D.5), (D.2) and (D.4) with respect to $z$ and evaluating the derivatives at $z=0$, I can express $d \mu / d z, d q^{R g} / d z$, and $d q^{G} / d z$ in terms of $d n / d z$. Differentiating (D.6) with respect to $z$, evaluating at $z=0$, and substituting the derivatives of $\left(\mu, q^{R g}, q^{G}\right)$, I get:

$$
\left[\frac{d n}{d z}\right]_{z=0}=\left[\frac{d \mu}{d z}\right]_{z=0}=0, \quad\left[\frac{d q^{G}}{d z}\right]_{z=0}=\frac{\theta \pi}{1+\theta} \frac{\psi(q)}{\psi^{\prime}(q)},
$$

where $q$ is given by (D.7). Finally, differentiating the welfare measure in (4.4) with respect to $z$ and evaluating at $z=0$, I obtain:

$$
\left[\frac{d v^{s}}{d z}\right]_{z=0}=\frac{1-\theta}{2(1+\theta)} \frac{\pi \psi(q) \alpha(n+g)}{(1+g)(1-\beta)} .
$$

This derivative is positive if and only if $\theta<1$. Recall that when $z=0$, the case focused on here exists only when $1 /(1+2 \mu)<\theta<1+2 \mu$. Thus, the legal restriction improves welfare if and only if $1 /(1+2 \mu)<\theta<1$. Under (3.2), this improvement occurs even when money growth is set optimally. This completes the proofs of Proposition 4.1 and section 4. QED 